\title{
The Role of Geometry on a Self-Sustaining Bio-Receptive Concrete Panel for Facade Application
}

\author{
Kazi Fahriba Mustafa ${ }^{1}$, Alejandro Prieto ${ }^{2, *(\mathbb{D})}$ and Marc Ottele ${ }^{3}(\mathbb{D}$ \\ 1 Department of Architectural Engineering + Technology, Faculty of Architecture and the Built Environment, \\ Delft University of Technology, 2628 BL Delft, The Netherlands; fahribamustafa18@gmail.com \\ 2 Architectural Facades \& Products Research Group, Department of Architectural Engineering + Technology, \\ Faculty of Architecture and the Built Environment, Delft University of Technology, \\ 2628 BL Delft, The Netherlands \\ 3 Department of Materials, Mechanics, Faculty of Civil Engineering and Geosciences, Management \& \\ Design (3Md), Delft University of Technology, 2628 CN Delft, The Netherlands; M.Ottele@tudelft.nl \\ * Correspondence: A.I.PrietoHoces@tudelft.nl
}

Citation: Mustafa, K.F.; Prieto, A.; Ottele, M. The Role of Geometry on a Self-Sustaining Bio-Receptive Concrete Panel for Facade Application. Sustainability 2021, 13, 7453. https://doi.org/10.3390/ su13137453

Academic Editor: Syed Minhaj Saleem Kazmi

Received: 8 June 2021

Accepted: 30 June 2021

Published: 2 July 2021

Publisher's Note: MDPI stays neutral with regard to jurisdictional claims in published maps and institutional affiliations.

Copyright: (C) 2021 by the authors Licensee MDPI, Basel, Switzerland. This article is an open access article distributed under the terms and conditions of the Creative Commons Attribution (CC BY) license (https:// creativecommons.org/licenses/by/ $4.0 /)$.

\begin{abstract}
Bio-receptivity refers to the aptitude of a material to allow for the natural growth of small plant species on stony surfaces with minimum external influence. Despite the numerous associated environmental benefits, the growth of mosses and lichens on facades has always been viewed as a negative phenomenon due to the random and shabby growth conditions. This research dealt with the design of a self-sustaining bio-receptive concrete facade system with an aim to create a more sustainable and green concrete for the construction industry. The research used surface geometry as a design variable to facilitate moss growth on concrete panels in an ordered and systematic manner. The exercise was an attempt to not only address the functional aspect of bio-receptivity but also its aesthetical quality, which has a primary influence on people's perception of bio-receptivity and can promote mass use of this type of concrete material. The research was conducted in a topdown approach, where first, through design by research, six distinctly designed concrete panels were fabricated using adapted material composition (blast furnace cement with $75 \%$ slag, 0.6 water / cement, sand $0-4 \mathrm{~mm}$ and gravel $5-8 \mathrm{~mm}$ ) as the boundary condition. The concrete mixture together with no curing policy resulted in highly porous concrete panels, suitable for bio-receptive properties. Next in the design validation phase, the influence of surface geometry/roughness on the water retention ability of the panels and the subsequent moss growth on the panels were evaluated through in vitro experiments. The water retention experiment of the panels was based on quantitative measurements for weight, relative humidity and temperature at several time intervals. The mossgrowing experiment was carried out within an ideal greenhouse condition where the panels were initially inoculated with moss spores; the results were based on qualitative observation for a period of 4 months. According to the comparative analysis of these results, with the same material composition, Panel 2 showed the highest bio-colonization owing to its prominent surface geometry, whereas Panel 5 showed the least bio-colonization owing to its plain surface despite high absorption capacity. Thus, the role of geometry has been extensively proven in this research and as an outcome a set of general design guidelines have been formulated for a self-sustaining bio-receptive concrete facade panel, using geometry as a design variable for bio-receptivity.
\end{abstract}

Keywords: bio-receptive facades; green concrete; surface geometry; moss growth; water retention; facade; roughness

\section{Introduction}

Concrete is one of the most popular construction materials in the world due to its strength and durability. However, despite its benefits, concrete production is also responsible for $8 \%$ of the global $\mathrm{CO}_{2}$ emissions [1]. A literal way to offset this is to grow plants on concrete to facilitate $\mathrm{CO}_{2}$ uptake [2-5]. Designing a concrete material that can be host 
to small plant species and micro-organisms without any superficial layer refers to the process of bio-receptivity. In 1995, Guillitte was the first person to define and recognize bio-receptivity, stating that 'The aptitude of a material (or any other inanimate object) to be colonized by one or several groups of living organisms without necessarily undergoing any biodeterioration [5]'.

Bio-receptive concrete material can be a solution to create a more sustainable version of this popular construction material for the future of net-zero buildings. As defined by Guillitte in 1995, bio-receptive concretes can be colonized by micro-organisms, macroorganisms and plants [5]. The green layer can protect the exposed material from harsh weather, and provide thermal and sound insulation [4]. By using the photosynthesis process, these small non-vascular plants can take in up to 3.9 billion metric tons of carbon per year [6]. The presence and the movement of water through the plant body contribute to cooling down the surrounding air by evapotranspiration [7], thus reducing the cooling load on the building. The structure of these plants is such that they are able to trap dust and other impurities, cleaning up the air to breathe [8]. Best of all, bio-receptive facades, being a result of the material property of the main building fabric, are viewed as self-sustaining systems (autonomous). This facade system requires no external irrigation or maintenance facilities, unlike the typical green wall systems.

When provided with the appropriate combination of material, environmental and plant properties, bio-receptive facades can prove to be an economically feasible greening medium. Material property is the most important factor to create a bio-receptive concrete facade. To achieve bio-receptivity, high surface roughness with high porosity and a neutral $\mathrm{pH}$ level is desired [2]. Physical properties like roughness and porosity are often valued over the chemical composition of the material, being the contributing factors for the presence of water on and within the surface $[9,10]$. Surface roughness can be defined as the topographic profile of the surface [11]. This degree of roughness helps to create a microclimate on the surface, by trapping in moisture from rain, dew and the accumulation of dust, and by providing the necessary shading from a harsh environment [12]. The amount of water that can be absorbed and retained in a material is determined by the level of porosity of the material [13]. As defined by Tran and Hoang [11], 'Porosity is the ratio of open pore volume to the total volume of materials.' A network of interconnected pores allows the permeability of water through the material, providing the moisture for survival of the micro-organisms. These physical properties together with a low $\mathrm{pH}$ around 8-10 have been reported to create the suitable chemical composition to make the material bio-receptive [5]. The $\mathrm{pH}$ value determines the alkalinity of the material, and binding materials like fly ash, slag or silica fumes have less hydroxyl ions, which help to create a neutral base to promote the plant growth [14].

Despite the reported benefits of a bio-receptive facade, it is often viewed as a deteriorating factor in building envelopes (Figure 1). In the public eye, the lack of order and shabby growth conditions of moss or lichens creates an impression of a dirty and damaged surface [12]. In recent times researchers have been trying different ways to redefine bio-receptivity and promote its benefits. Some of the notable works are the research work in University College London, UCL Bartlett, in 2016, where Professor Cruz and Beckett tested digitally fabricated (glass fiber-reinforced concrete) GRC limestone concrete panels transplanted with moss to create growable concrete blocks [2]. Another early exploration in this field was by Ottele et al. in 2010, where the geometry of the top layer of the concrete panel was used to foster plant growth on its surface. His experiment also showed a clear dependency of plant growth on the material property [4]. Lastly, Huang et al. tested the role of different micro-grooves for the formation and growth of microalgae biofilm [15]. In line with the cited research experiences, this research is a further exploration into the relevance of geometrical articulation of a surface on its potential for bio-receptivity. Here, the problem has been addressed to stimulate bio-receptivity through solutions based on real time practical experimentations. 


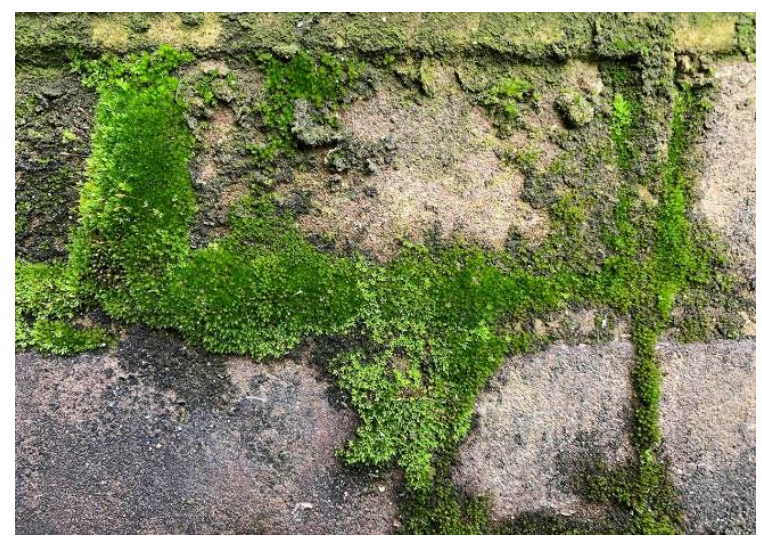

Figure 1. Natural moss growth on masonry.

The main objective of this research was to explore the impact of geometry on the ordered growth of mosses, in order to highlight its benefits and promote (mass) the use of these bio-receptive concrete facade panels. Geometry has been used to facilitate the ordered and systematic growth of mosses on concrete facade panels, resulting in an aesthetically pleasing and functional surface layer. The research followed a top-down approach where, first, designs were developed based on the literature and field surveys, and these were then validated through practical experimentations and simulations, finally providing a general design guideline for the use of geometry as a design variable in the development of bio-receptive facade panels.

\section{Strategy and Methods}

To achieve the research goals, the methodology followed here was a top-down approach. The approach was divided into two main stages. The first stage involved the formulation of the design scenarios, where designs were developed based on literature research and field surveys. The second stage was the experimental setup, where the designs were validated through experimentation to create a set of design guidelines that can enhance the bio-receptive quality of concrete panels. In the first stage, the boundary conditions were set for the concrete mixture according to the research results from the doctoral dissertation of Manso [3], used to fabricate the designed panels. In the second stage the moss-growing experiment was carried out within a controlled environment in a greenhouse, assuming an ideal growth condition (temperature $20-24{ }^{\circ} \mathrm{C}, \mathrm{RH} 75-85 \%$ ), while the water retention experiment was setup in a laboratory replicating the effect of rainfall onto the surface of the concrete panels. Due to time restraints, carrying out the experiments in outdoor conditions was not within the scope of this research.

\subsection{Definition of the Design Scenarios}

In this section, the first stage of the top-down approach has been discussed, where following the design of the research strategy, prototype designs were developed. The research began with a thorough literature review on the plant biology of mosses, material properties of concrete, environmental properties, influence of geometry on bio-receptivity and field surveys.

The literature review and practical insight from the field survey provided an outline to design several geometrical options to facilitate engineered moss growth on concrete. According to the studies, mosses are non-vascular plants, with no root system, which take in water through capillary action. Mosses require water to carry out the fertilization process and wind for spore dispersal [8]. Being poikilohydric, mosses that are found in exposed surfaces often grow in tufts or cushion form to minimize water loss [16]. Mosses, being small plant species, need to have a microclimate on and above the surface. The micro-climate can help to maintain the required moisture level, a cooler temperature and a 
low wind speed. The role of geometry is vital to create the desired micro-climate conditions for this plant growth.

An engineered growth refers to employing surface geometry to create a self-sustaining system for the growth of mosses in desired areas and in a desired coverage. The presence of water is essential for the growth and development of bio-colonization [17]. The surface roughness, being the most crucial physical characteristic of the material, should be able to retain water from the rain, dew and other natural phenomena on its surface $[12,17,18]$. The surface morphology can also help to create areas of shading to protect plants from direct sunlight and provide buffers to high wind speed causing detachment and also gather nutrients onto its surface.

Based on this parameter, four distinct geometric panels were designed, catering to the environmental factors for a self-sustaining system (Figure 2). The geometric features of each designed panel were classified into two geometry levels, macro- and micro-level geometry. A combination of both these geometric levels helped to create a micro-climate within its surface by influencing the water flow path of the panels and direct growth in desired areas. The micro-geometric features, called micro-grooves, were used where moss coverage was desired, creating slow water movement into water catchment areas and anchorage facilities. The macro-geometric features created the overall surface undulations, which helped to distinguish between the growth and no-growth areas. Two extra panels, a plain concrete panel and a naturally rough concrete panel with exposed sand and gravel layers, were also created for a more vivid comparative analysis between the ordered and random surface geometries (Figure 2).
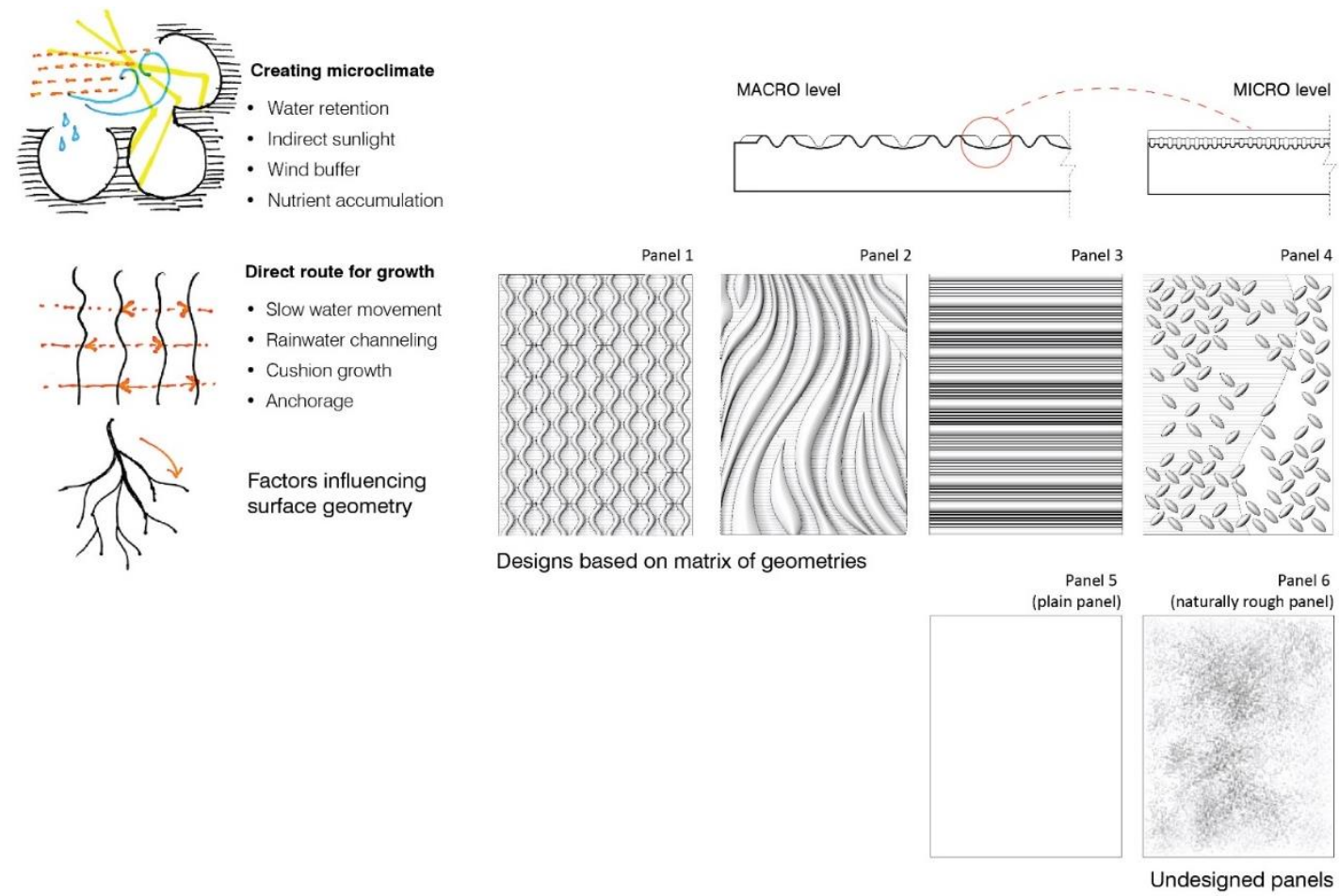

Figure 2. Proposed design scenarios.

To maintain an aesthetically pleasing look to the designed geometric panels, the geometric compositions investigated in this research were inspired by patterns found in nature depicting different functional qualities. The patterns were further translated into surface geometry on the four panels through a method of repetition called rhythm, creating a sense of harmony and order that is aesthetically pleasing to the human eye (Figure 3) [19]. Panel 1 has been designed in an alternating rhythm method, Panel 2 in a flowing rhythm, Panel 3 in a regular rhythm and Panel 4 followed a random rhythm. 


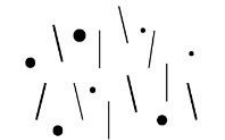

Random rhythm

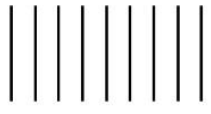

Regular rhythm

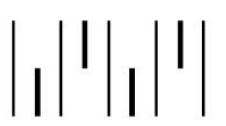

Alternating rhythm

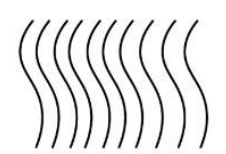

Flowing rhythm

Figure 3. Types of rhythm.

To achieve bio-receptivity, the concrete needs high surface roughness with high porosity and a neutral $\mathrm{pH}$ level [2]. To further proceed with a foolproof concrete mixture with bio-receptive properties, the recipe was adapted from the doctoral dissertation of Manso. Factors like the type of binder to be used, the aggregate sizes, the water/cement ratio and the amount of cement paste determined the material composition for bio-receptivity [3]. Table 1 shows the material content for $1 \mathrm{~m}^{3}$ of concrete. For detailed calculation, refer to Appendix A (Figure A1).

Table 1. Boundary conditions for concrete recipe Amount shown for $1 \mathrm{~m}^{3}$.

\begin{tabular}{cc}
\hline Materials & Quantity (kg) \\
\hline $\begin{array}{c}\text { CBR CEM III/B 32.5 N } \\
\text { Blast furnace cement (75\% slag content) }\end{array}$ & 300 \\
\hline Dry sand (0-4 mm) & 740 \\
\hline Dry Jurassic yellow gravels (5-8 mm) & 1142 \\
\hline Water (water cement ratio, w/c 0.6) & 180 \\
\hline
\end{tabular}

The prototype making process was carried out as following. The negatives of the four prototype designs were fabricated through CNC milling on hard foam material. The foam molds were next brushed with a sealing agent, silicone, to reduce their adhesion quality to concrete and ensure easy demolding (Figure $4 \mathrm{a}$ ). Finally, after $24 \mathrm{~h}$. of hardening, the molds were filled with the prescribed concrete mixture (Figure $4 \mathrm{~b}$ ). The mixture was left to set uncovered in the molds for $48 \mathrm{~h}$ without any curing to achieve the highest possible porous quality of the concrete panels. In total, 12 concrete panels in the size $350 \times 250 \times 40 \mathrm{~mm}$ were made. For each tile, $3.25 \mathrm{~L}$ of the mixture were cast into the molds. Among the two sets of the concrete panels cast, one set was used for the macro-level water-related laboratory testing and the other set for the controlled moss growth experiment.

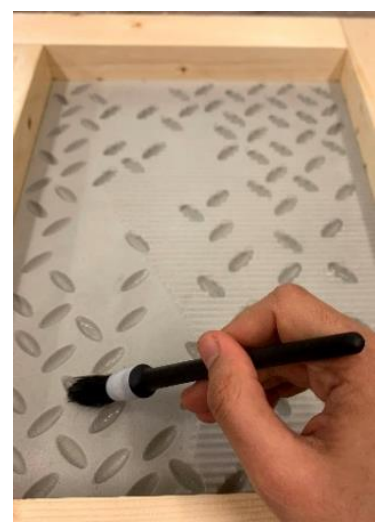

(a)

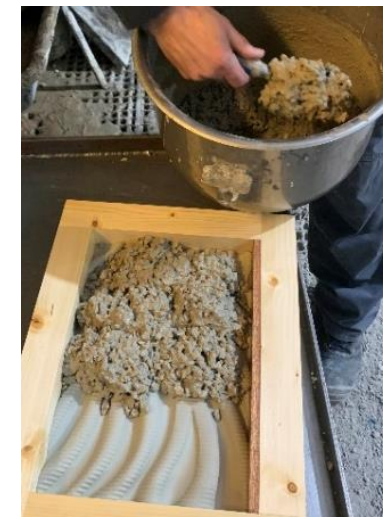

(b)

Figure 4. (a) Coating the designed molds with releasing agent; (b) casting the concrete panel(s).

\subsection{Experimental Setup}

\subsubsection{Water Retention Experiment}

As already found, water is essential for the growth and survival of mosses. The designed geometric patterns on the concrete panels have been used to influence the water 
flow movement on and within its surface. To test and validate this hypothesis, the following water retention testing was carried out in a laboratory setup. The goal of this experiment was to measure how much the weight of each of the panels changed due to their water absorption and retention capacities, which were solely influenced by the surface geometry of each panel irrespective of their material composition.

The experiment began with the laboratory setup as shown in Figure 5, the panel was placed over a waffle grill to allow the sprayed water to drain out into the tray below. Next, a camera was set from a suitable distance to record the water movement on the surface. For better visibility, water soluble beetroot juice was diluted with water for spraying. A pressure water sprayer with a $30^{\circ}$ nozzle angle was filled with the red-color water and positioned at a fixed distance of $25 \mathrm{~cm}$ from the concrete block. Black tap markings were used to demark the standing position for spraying, the distance of the spray nozzle from the block and the position of the tripod for the camera. The room temperature was measured to be $22{ }^{\circ} \mathrm{C}$ and $\mathrm{RH} 55 \%$ for the record.

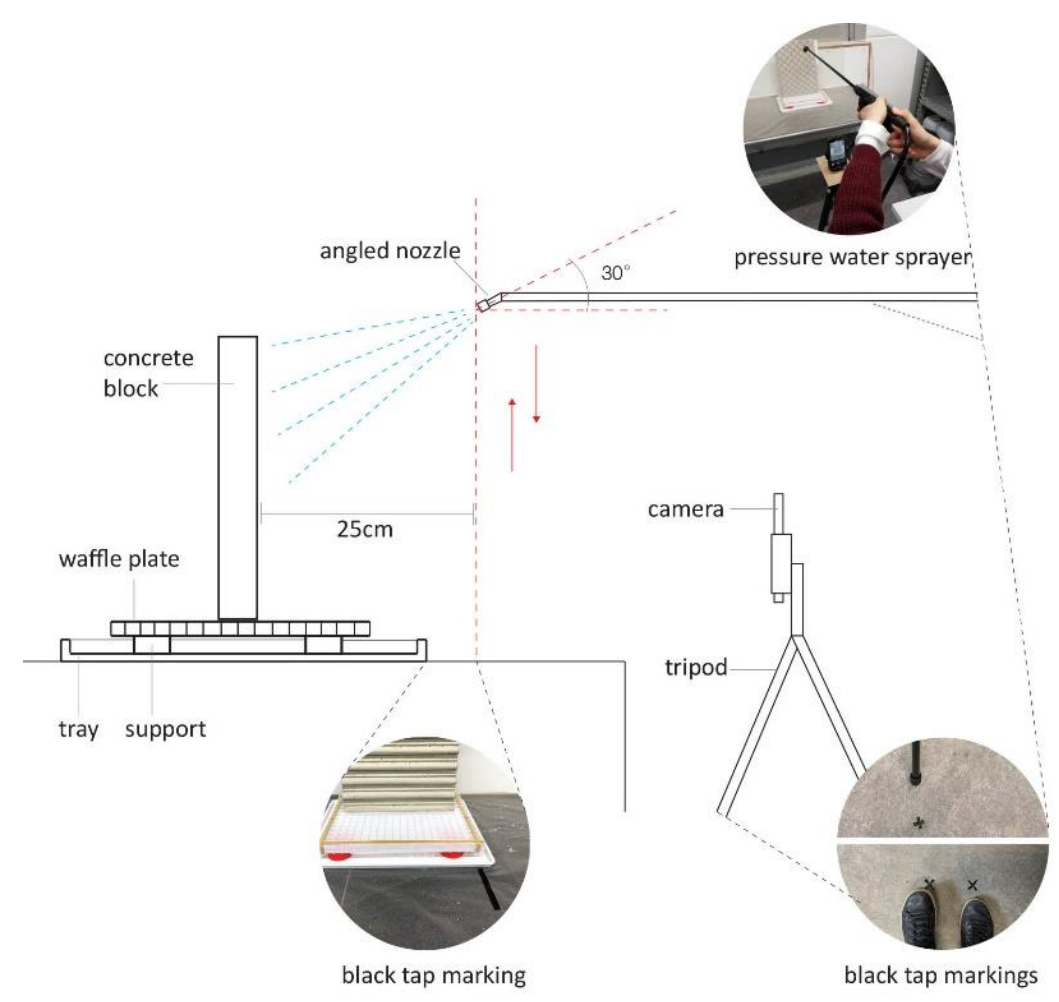

Figure 5. Setup for water retention testing on concrete panels.

The ridge part of the designed panel surfaces was sand polished to smoothen it for efficient redirection of water from ridges towards the alcove. Next, the panels were oven dried for a period of $6 \mathrm{~h}$ at $45^{\circ} \mathrm{C}$. The oven drying was only done once at the beginning of the experiment to ensure complete drying of the panels. The experiment was carried out in the following steps:

Step 1: The weight before spraying was recorded.

Step 2: The panels were calibrated vertically according to the setup described in the previous section.

Step 3: The colored water measuring $150 \mathrm{~mL}$ was sprayed for a duration of $30 \mathrm{~s}$, in an up and down motion of the sprayer to allow even wetting of the panel.

Step 4: After a period of $2 \mathrm{~min}$, the amount of water drained out into the tray was measured and the readings for temperature, surface relative humidity and weight of the panels were recorded.

Step 5: The temperature, humidity and weight readings were recorded twice more, after $10 \mathrm{~min}$ and $20 \mathrm{~min}$ from the spraying time (Figure 6a-c). 


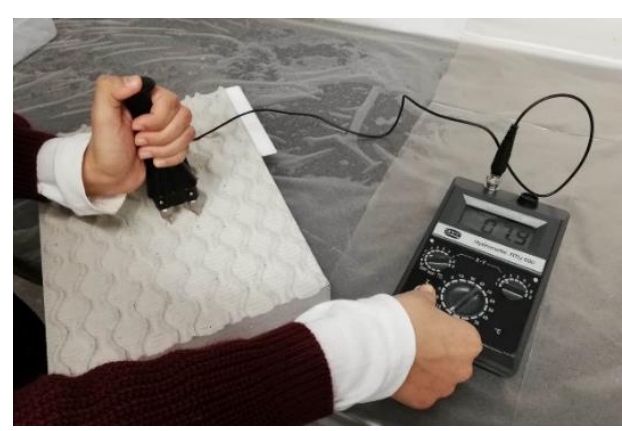

(a)

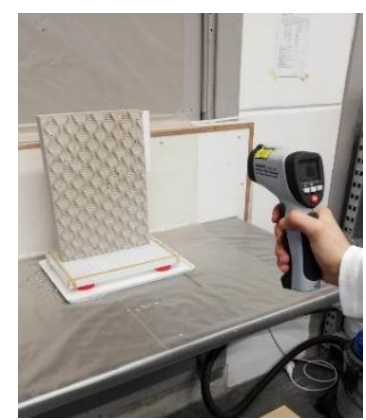

(b)

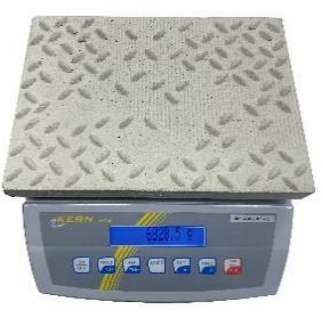

(c)

Figure 6. (a) Relative humidity measurement; (b) temperature recording; (c) weight recording.

The procedure was repeated for day 3 and day 7 to test the water retention ability of the panels over a period of 7 days. The whole laboratory setup and experiment procedure was repeated a second time to check for any discrepancies in the two sets. In the results section, all the data from the experiment have been thoroughly documented and analyzed to further deduce the findings.

\subsubsection{Moss-Growing Experiment}

The second set of the freshly cast panels were used for the moss-growing experiment. The experiment was carried out in the greenhouse of the TU Delft botanical garden. The experiment was dated between the end of February to mid-May, after a trial phase for the first three weeks of February.

The saxicolous moss fragments with rip spores were collected from the botanical garden stone surfaces. The slurry was prepared, according to the findings of our literature review. Buttermilk and moss fragments in a (1:1) ratio were blended for $24 \mathrm{~h}$ before application. The buttermilk helped to create an acidic base for the mixture. The panels were prepared by polishing the ridges with sandpaper for a smoother finish where no moss growth is desired and then thoroughly cleaned with water and vinegar to remove any surface contaminants. The prepared slurry was painted in desired areas using a paint brush.

Based on the findings of the trial period, the panels recoated with moss slurry were placed in the warmer tropical greenhouse. The experiment was carried out in a span of 12 weeks. It was done in two phases, where during first 6 weeks, the panels were placed in horizontal position, and for the last 6 weeks, in an upright position (Figure 7). The temperature ranging between $20-24{ }^{\circ} \mathrm{C}$ and $\mathrm{RH} 75-85 \%$ was maintained within the greenhouse and rainwater was sprayed onto the panels twice or thrice daily for around 30 s each time depending on the weather conditions. During the dark cycle of the day, the panels were kept uncovered due to the high humidity ( $\mathrm{RH} \mathrm{60 \% +)} \mathrm{inside} \mathrm{the} \mathrm{greenhouse.}$

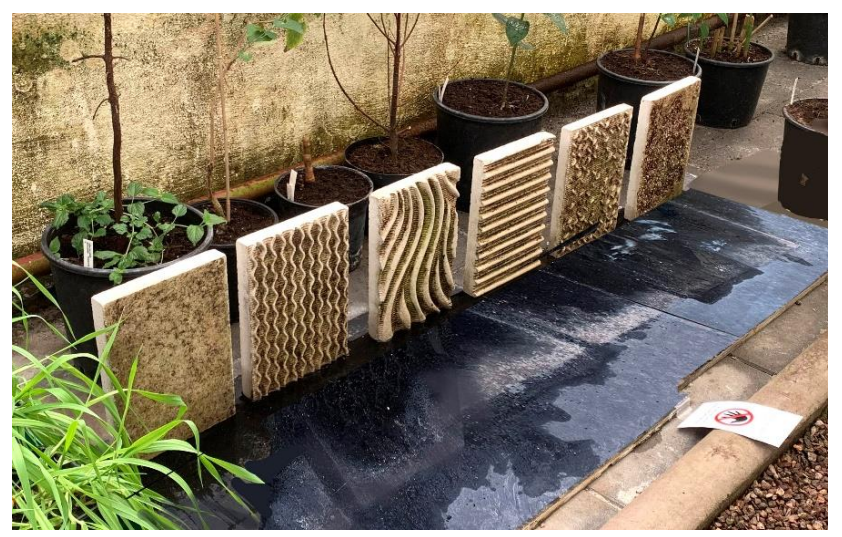

Figure 7. Warmer tropical greenhouse (average temperature $20-24^{\circ} \mathrm{C}$ ). 


\section{Results}

\subsection{Results of Water Retention Experiment}

The results for the water retention experiment were analyzed in four sections: change in weight, ridge and alcove relative humidity, change in temperature and visual analysis of water movement on the surface of the six panels.

\subsubsection{Change in Weight}

In Figure 8a, the graph shows an average change in weight value at $2 \mathrm{~min}$ and $20 \mathrm{~min}$ after spraying for the total 6 days of readings. Due to a gradual drop in weight at $2 \mathrm{~min}$, $10 \mathrm{~min}$ and $20 \mathrm{~min}$, the bar chart only shows the change in weight values for $2 \mathrm{~min}$ and $20 \mathrm{~min}$.

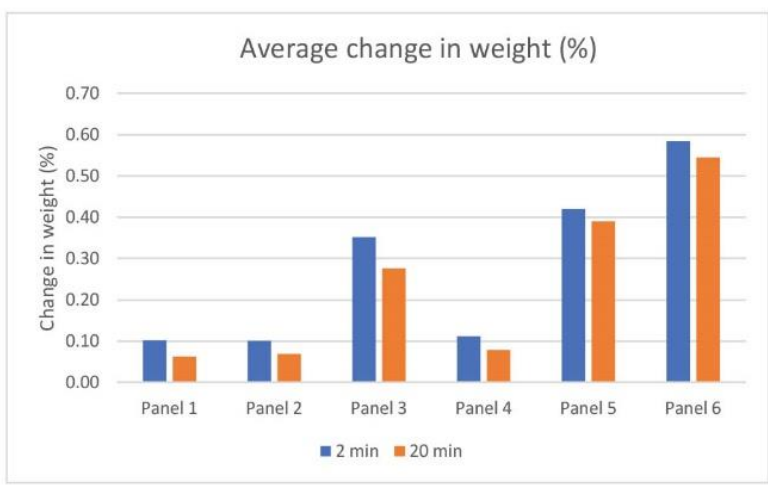

Weight gain in relation to initial weight

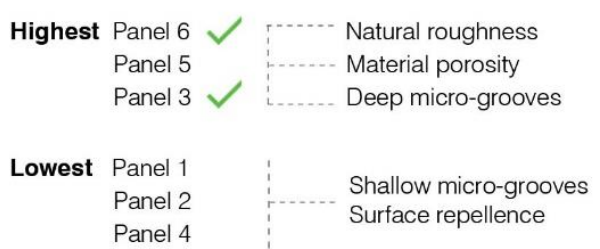

(a)

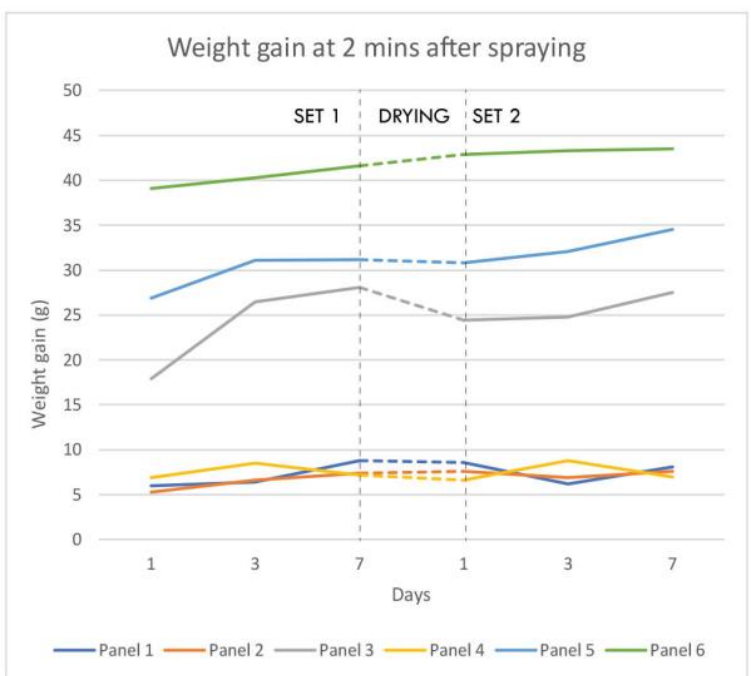

Weight gain at 2 mins after spraying

$\begin{array}{lrr}\text { Highest } & \text { Panel 6 } & \text { Range }(39-44 \mathrm{~g}) \\ & \text { Panel 5 } & (27-35 \mathrm{~g}) \\ & \text { Panel 3 } & (18-28 \mathrm{~g})\end{array}$

Exception: Panel 5 shows high water absorption due to absence of surface repellent quality and exposed material porosity.

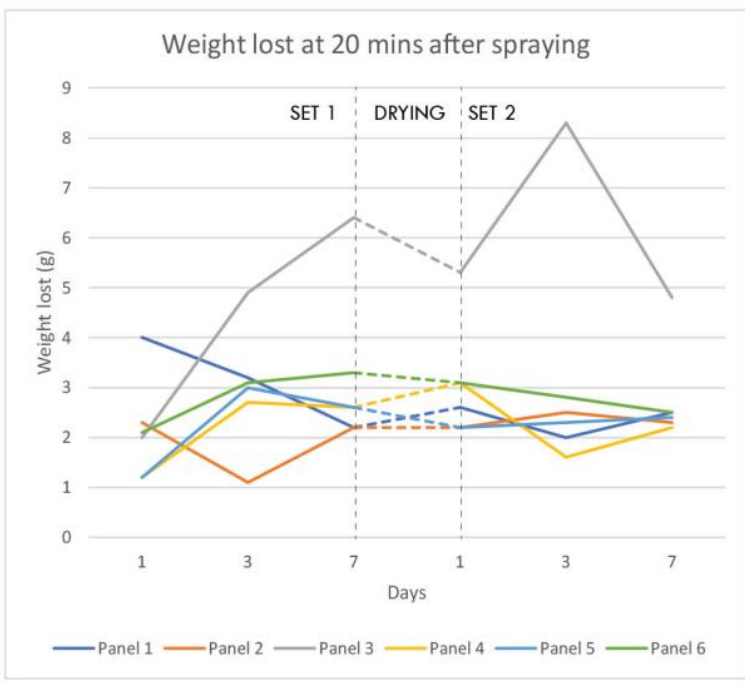

Weight lost at 20 mins after spraying

$\begin{array}{lll}\text { Highest } & \text { Panel } 3 & \text { Range }(2-8 g) \\ \text { Lowest Panel } 2 & \text { Range }(1-2.5 g)\end{array}$

Note: Panel 6 shows 2nd highest weight loss due to its rough surface quality.

(b)

Figure 8. (a) Average change in weight; (b) weight gain at 2 min after spraying for all 6 days; (c) weight lost at 20 min after spraying for all 6 days. 
The average change in weight expressed as a percentage of its initial weight at $2 \mathrm{~min}$ was found to be highest for panel 6 and panel 5, respectively. Panel 6 showed the highest weight gain owing to its natural surface roughness, while panel 5, contradicting its plain surface, showed the second highest weight gain. Due to the absence of a surface repellent layer, panel 5 exhibited the high porous quality of the concrete itself. Panel 3 also showed moderately high weight gain value owing to the water catchment into its deeper recessed spaces, but it also showed the highest weight lost at 20 min due to loss of its surface water. Panels 1, 2 and 4 showed the least weight gain at $2 \mathrm{~min}$, mostly owing to their shallow micro-grooves and the presence of the surface repellent layer adhered from the mold surface while casting.

Figure $8 \mathrm{~b}$ shows a cumulative display of values for weight gain at $2 \mathrm{~min}$ for the two sets of experiments. Panel 6 and panel 5 showed the highest gains, with a nearly steady increase in weight gained at 2 min for all six days. Panel 3 showed the highest fluctuation in weight gain due to surface water lost during transport for weight measurement. An over-time increase in weight gain was seen for Panels 6, 5 and 3, which is presumed to be due to a break in water tension in the capillary pores of the concrete panels. However, Panels 1, 2 and 4 showed a mirror result for set 2, owing to their poor water relation qualities.

Figure $8 \mathrm{c}$ shows a cumulative result for weight lost at $20 \mathrm{~min}$ for all the six days of the experiment. Panel 3 showed the highest weight loss with the highest fluctuation among the six days, which was due to different amounts of surface water lost on each day. Panel 6 showed an improvement in absorption capacity, with descending weight loss values in set 2 , owing to its natural rough surface. The rest of the panels showed high fluctuation in weight loss in set 1 moving towards lower fluctuations in set 2 , with Panel 2 reaching a flattened curve.

Therefore, from the two sets of values, it can be seen, that panel 6 with natural roughness showed the highest weight gain and very low weight loss along the six days. This can be explained due to the absence of the surface repellent layer and the deeper surface roughness. In terms of the designed panels, it was noticed that the panels with deeper recessed spaces and micro-grooves retained more water on the surface, resulting in more water absorption into the panels, and these were found to be two important learnings to be further implemented into the design guidelines.

\subsubsection{Alcove and Ridge Relative Humidity}

Due to the 3D patterns on the surface, largely two horizontal surface planes were present, made up of an alcove, the recessed part and ridge, and the raised part, giving two types of relative humidity $(\mathrm{RH})$ values. The alcove/ridge readings for the $\mathrm{RH}$ were taken at three different points, top, middle and bottom along the middle of the panels (Figure 9a). This was done to get a more distinct range of moisture values through the concrete surface. The alcove/ridge readings were taken at $2 \mathrm{~min}, 10 \mathrm{~min}$ and $20 \mathrm{~min}$ after spraying and repeated for two sets of experiment.

As in Figure 9b, for alcove moisture, panel 3 showed the highest $\mathrm{RH}$ values at both $2 \mathrm{~min}$ and $20 \mathrm{~min}$, with a slight dip in alcove moisture at $10 \mathrm{~min}$. The high value was due to the presence of deeper alcove spaces with $4 \mathrm{~mm}$ deep micro-grooves, positioned against the flow obstacles, which created more hindrance to the linear flow path compared to other panels. Panel 6 showed a significant drop in alcove moisture from 2 min to 20 min due to both its high absorption capacity and high surface evaporation. All other panels showed low and nearly constant RH values, due to their shallow groove depths.

As in Figure 9c, Panel 3 showed an increase in ridge moisture over time, owing to its against the flow macro geometry, which gradually got more wet as the water dripped down from the alcove to the ridges. For Panel 6, the ridge moisture was the same as the alcove moisture results. All the other panels showed low and nearly constant values through time, with panel 2 showing the lowest ridge moisture due to its lower ridge surface area. 

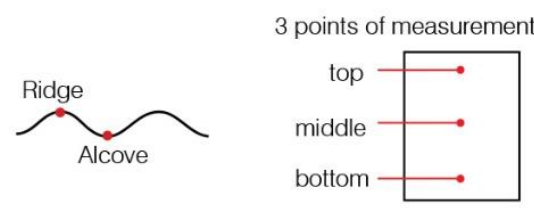

(a)

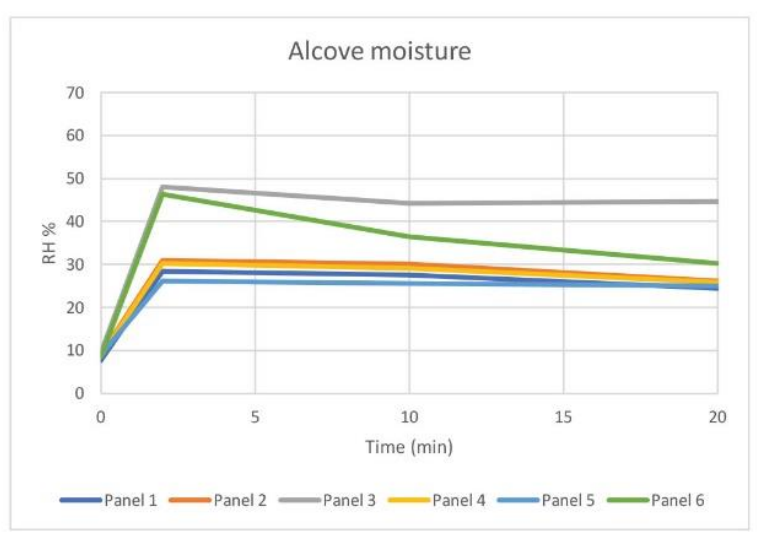

Alcove moisture after $\mathbf{2}$ min

Highest Panel 3 Range ( $\mathrm{RH} 26.8-61.2 \%)$

Lowest Panel $5 \quad(\mathrm{RH} 23-30 \%)$

Alcove moisture after $\mathbf{2 0} \mathrm{min}$

Highest Panel 3 Range ( $\mathrm{RH} 34.3-58.4 \%$ )

Lowest Panel $1 \quad$ (RH 17.3-29.6\%)

(b)

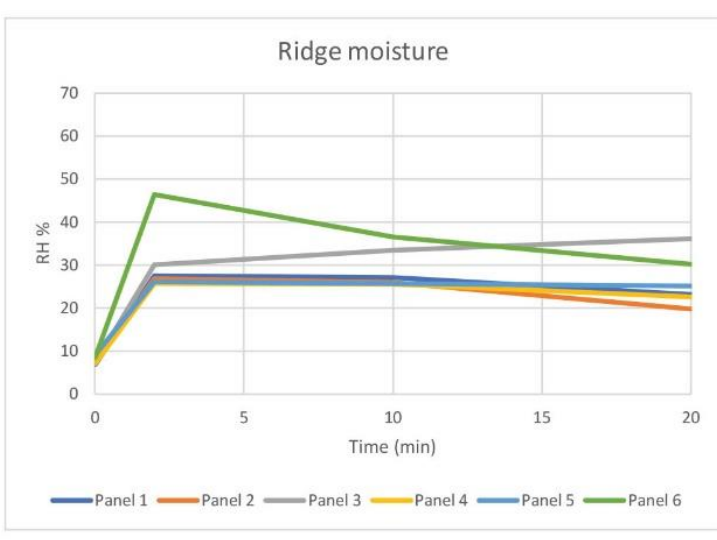

Ridge moisture after 2 min

Highest Panel 6 Range ( $\mathrm{RH} 33.5$ - 55.6\%)

Lowest Panel $4 \quad$ ( $\mathrm{RH} 20.7-29 \%)$

Ridge moisture after $\mathbf{2 0} \mathrm{min}$

Highest Panel 3 Range (RH $29-43.5 \%) \quad$ Against the flow

Lowest Panel $2 \quad(\mathrm{RH} 11-29.5 \%) \vee \begin{aligned} & \text { Wider and highe } \\ & \text { macro-grooves }\end{aligned}$

(c)

Figure 9. (a) Alcove and ridge points of measurements; (b) average alcove relative humidity; (c) average ridge relative humidity.

Therefore, it could be concluded that greater surface undulations help the water to dry out slowly, working as a shield, as was evident from the results of Panel 6. Though at $2 \mathrm{~min}$, it showed high surface moisture, at $20 \mathrm{~min}$, due to it very low surface undulations, its rate of evaporation was also very high. Another aspect that was noticed was the against the flow macro-geometries were contradicting the idea of distinct growth and no-growth areas. As it was seen in case of Panel 3, the water dripped down from the alcove to the ridges, blurring the surface distinction desired.

\subsubsection{Change in Temperature}

The temperature readings were taken to see the cooling effect of the concrete panels after spraying water onto the surfaces. All the panels showed an initial temperature of $20-21^{\circ} \mathrm{C}$. After spraying at $2 \mathrm{~min}$, the panels showed a sharp decrease in temperature by $2-3{ }^{\circ} \mathrm{C}$ and in the $10 \mathrm{~min}$ and $20 \mathrm{~min}$ readings, the temperature gradually increased by $0.5^{\circ} \mathrm{C}$. The results were found to be similar for all the panels, which could be due to the same material composition of the panels. The different surface geometries seemed to have no significant effect on the cooling effect of the surface, and thus the results were not further analyzed.

\subsubsection{Visual Representation of Surface Water Movement}

As in Figure 10, the visual representation helped to get a live picture of the behavior of water on the surface. These visual results of the water movement pattern on the surfaces helped to further strengthen the results from the change in weight, and ridge and alcove 
relative humidities. The accumulated results from the water retention experiment were used to draw out a practically driven and verified set of design guidelines to enhance the bio-receptivity characteristics of the concrete panels.

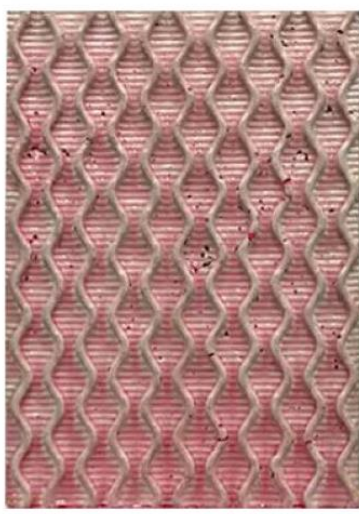

\section{Panel 1}

Due to the shallow micro-grooves, there is no water retention possible, water is dripping out in straight lines. The thin and low depth macro-geometries make it difficult to create a distinction between growth and no growth areas.

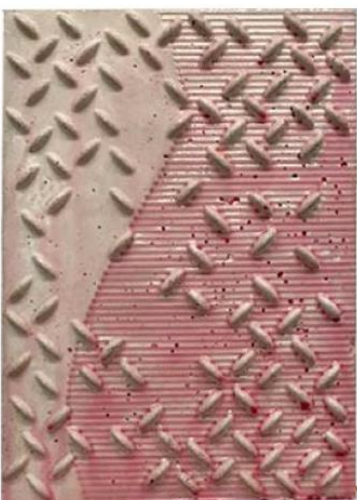

Panel 4

The shallow micro-grooves help to retain more surface water compared to smooth surface, showing a clear distinction on surface performance. The size and the discontinuous nature of the macro-geometries make it difficult to direct growth.

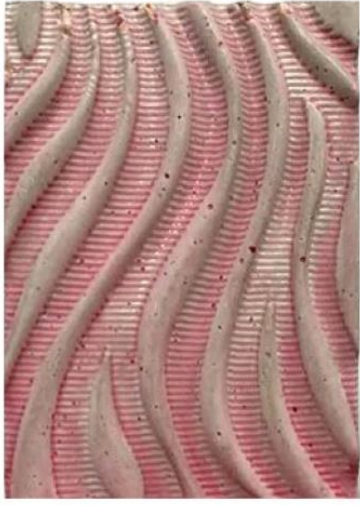

\section{Panel 2}

The wider macro-geometries with greater height helps to redirect water towards the micro-grooves, showing higher concentration of water in the growth areas. Due to the shallow micro-grooves, water catchment is not possible.

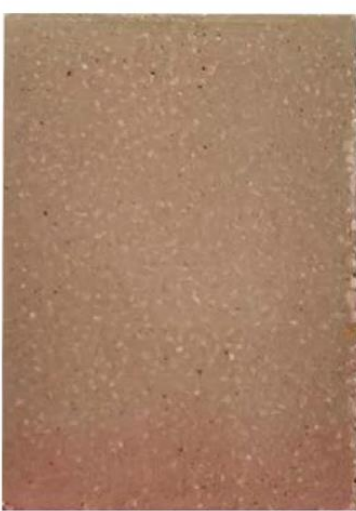

\section{Panel 5}

The plain surface shows no obstruction on water movement causing quick drying of the surface. The porous quality of the concrete material increases the absorption capacity due to absence of surface contaminants (release agents).

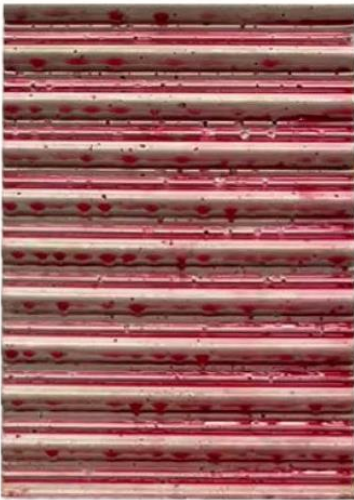

\section{Panel 3}

The against the flow macrogeometries create an obstacle to water flow, allowing more water retention into the deep alcove spaces. These obstacles also keep the ridges constantly wet, making it difficult to direct growth route.

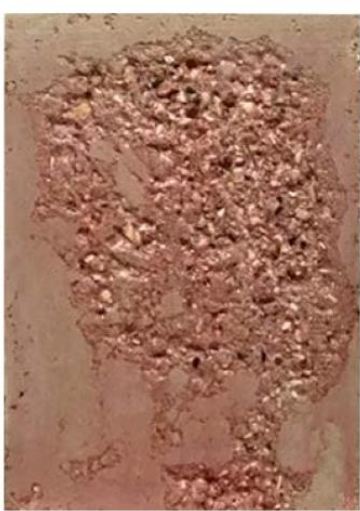

Panel 6

The natural rough surface texture allows water retention into it depth, showing more red patches. The absorption quality of the panel is also high due to porous material quality and absence of surface contaminants.

Figure 10. Visual representation of water movement on the surface of the panels at the end of $30 \mathrm{~s}$ of spraying.

\subsection{Results of Moss-Growing Experiment}

\subsubsection{Trial Results}

During the 3 week trial, some important information was learned, which greatly influenced the moss growth. The best temperature to accelerate moss growth was found to be between $20-24{ }^{\circ} \mathrm{C}$, though according to literature, the most suitable temperature was around $15{ }^{\circ} \mathrm{C}$. The growing process was prolonged in the colder temperature and was not suitable for a controlled growth within a short time. After about 7-8 days of application, signs of fungus growth were observed over the applied slurry. This process is called symbiosis, where two organisms living together undergo an ecological interaction. 
Symbiosis is known to exist in the early stages of plant growth, where both the parties benefit from an increase in the uptake of nutrients [20]. This stage is the early colonizing phase by the fungi and spores before the appearance of moss (Figure 11).

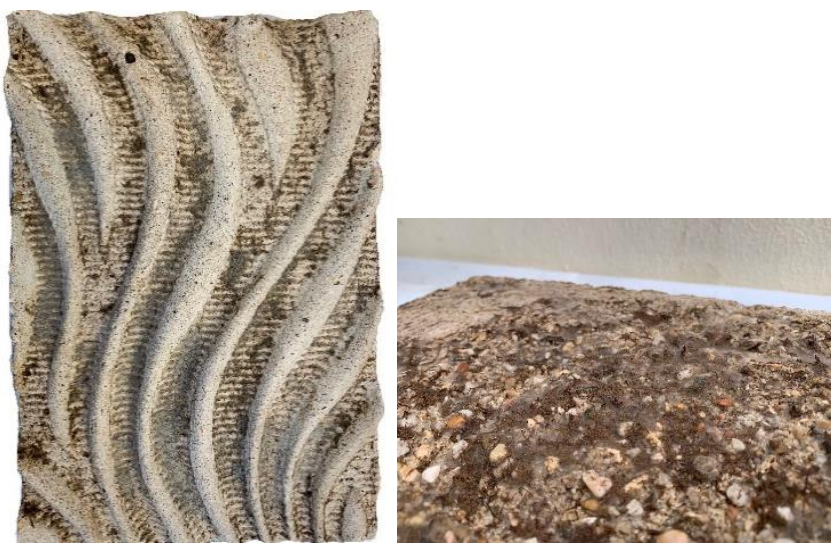

Figure 11. Fungus growth on the panels (symbiosis).

\subsubsection{Bio-colonization Results}

After the trial period, the first 6 weeks, the panels were kept in a horizontal position to allow them to remain wet for a longer time and create the required moist conditions for moss growth. Around the fourth week, small patches of green algae were seen on the surface of Panel 2, while the others remained unchanged as dark brown. During the six-week, bright green layers of algae had grown in the central alcoves of Panel 2, while light patches were also seen in Panels 1,3 and 4, mostly around their central areas, due to the higher concentration of water spraying along this region. Among all the panels, the macro geometry of Panel 2 had the greatest depth, which allowed higher water retention on the surface and subsequently more algae formation. The appearance of the green algae indicated the bio-receptive character of the concrete panels (Figure 12).
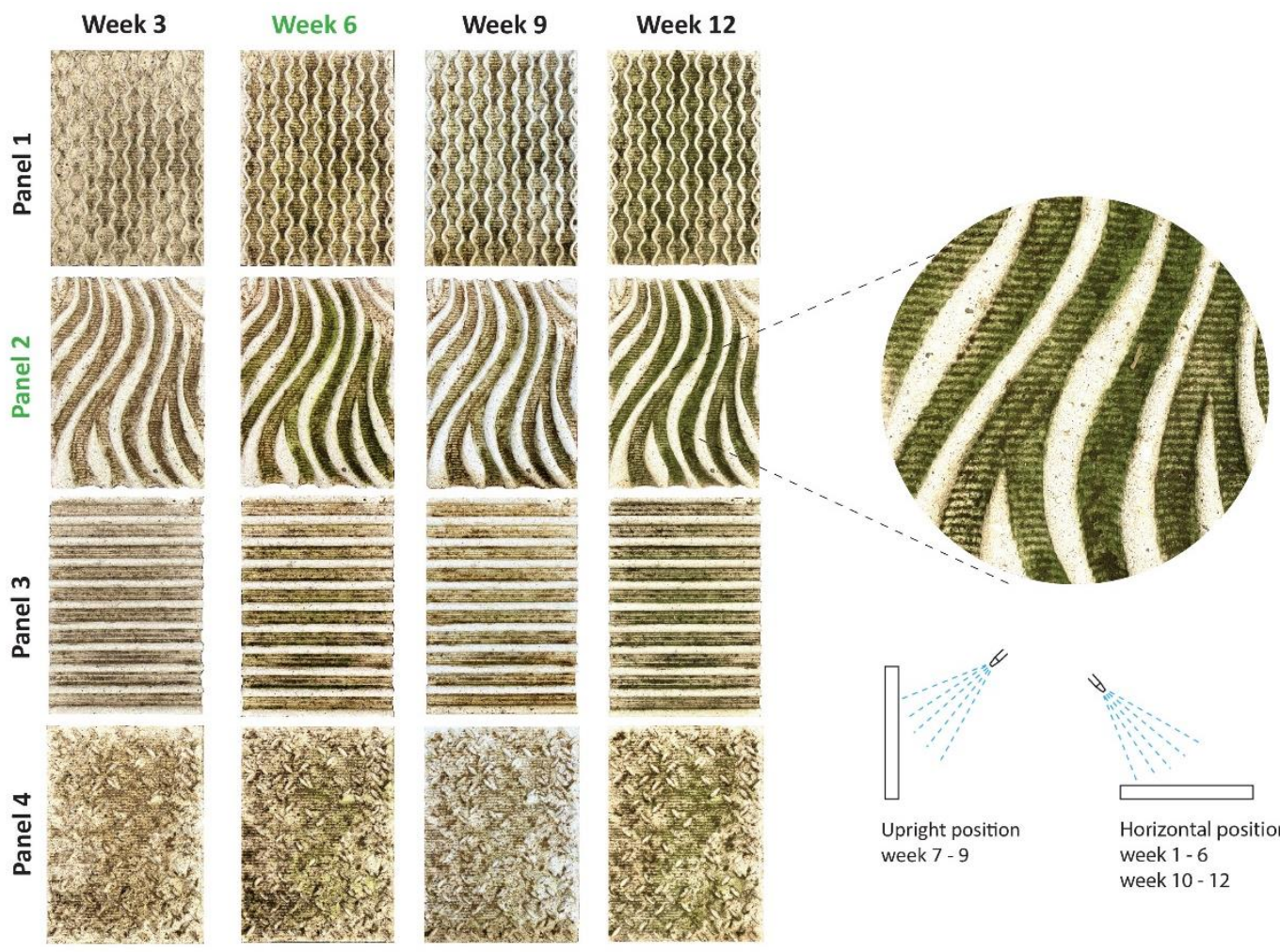

Figure 12. Photographic observation of the 12-week growth pattern for the 4 panels. 
At the end of week 6, all the panels were placed in an upright position, to observe the role of geometry on water flow movement on the surface of the panels. After a week, the green patches on the panels appeared lighter and the panels seemed drier than before. The sudden change was assumed to be for two reasons, firstly, around mid-April, due to warmer outside temperature, the tropical greenhouse recorded a high temperature of $32{ }^{\circ} \mathrm{C}$, resulting in rapid drying by evaporation, and secondly, the upright position allowed less time for the water to remain onto the surface due to the lack of deeper water catchment micro-grooves (Figure 12).

In week 8 , the panels were shifted to another region of the greenhouse, to maintain a temperature of $20-24{ }^{\circ} \mathrm{C}$ and slow down the drying effect. The progress was still found to be minimal. Thus, from week 10 onwards, the panels were laid horizontally again, to increase the water retention onto the surface. By the beginning of week 12, bright green patches of algae were seen on the textured surfaces. Panel 2, showed the highest growth, followed by Panel 1, owing to their textured macro-depths and continuous flow paths, allowing for trail growth in desired areas.

Therefore, from the above experiment, the following points need to be considered to enhance the moss-growing capacity onto the panels:

- Twelve weeks is not enough to propagate moss growth on concrete surfaces.

- Estimated time for algae appearance is 8-12 weeks and for moss growth it is 18-20 weeks.

- The panels should be placed in a horizontal position until visible moss growth occurs.

- Panels should have growth areas of connected macro-depths to allow continuous trails of growth and deep micro-grooves to allow sufficient water retention ability for a prolonged period when placed in a vertical position.

- Further testing is required for mature moss-grown panels in vertical positions, extending the spraying duration to 2 min once daily, for a period of approx. 3-4 weeks.

\section{Discussion of Results}

\subsection{Comparative Analysis}

Based on the results of the design validation section, the moss-growing experiment and the water retention testing, this section has provided a comprehensive guideline for the design of bio-receptive concrete panels.

Figure 13 is a comparative chart between the water retention/absorption capacity of the panels and the practical moss growth progress in the greenhouse. In terms of the water relations, Panels 3, 5 and 6 showed the best results. Panel 3 had higher surface water due to deeper alcove spaces and against-the-flow obstacles. Panels 5 and 6 showed high absorption compared to the other panels due to the absence of surface contaminants like silicone oil. For the designed panels, the silicone oil used in the molds for easy demolding left a residue layer over the concrete surface. The silicone oil, having high water-repellent capacity, hindered the absorption of water into the designed panels. In spite of the high absorption capacity, Panels 5 and 6 were not suitable for the ordered growth desired in this research. Even though Panel 3 showed the highest amount of surface water, water dripped from the alcove to the ridges due to the horizontal alignment of the macro-geometries (positioned against the main flow). The idea of steering in growth/no-growth areas did not work here, hence it hindered the ordered (pattern) growth requirement. The results from the greenhouse were obtained from week 12. Panel 2 showed the highest algae coverage on the surface, followed by Panel 1, due to the along the flow obstacles. The design features of Panel 2 provided a clear distinction between growth and no-growth areas, with its deeper and wider macro-geometry creating moist conditions on the surface in the horizontal position. However, a drastic drop in growth occurred when the panels were placed in vertical position. This was due to the quick drying of the surfaces from absence of enough water catchment areas. Though Panel 3 showed a good amount surface water, it failed to show adequate moss growth due to limited growth areas and insufficient micro-groove presences. 


\begin{tabular}{|c|c|c|c|c|c|c|c|c|c|}
\hline $\begin{array}{l}/ / \triangleleft \\
\text { OBSTALLE } \\
\text { DIRECTION }\end{array}$ & $\begin{array}{l}\text { GROOVE } \\
\text { DEPTH }\end{array}$ & 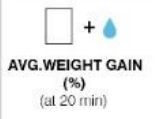 & 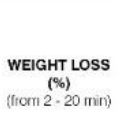 & 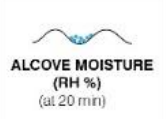 & 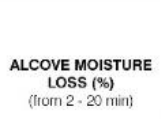 & $\begin{array}{l}\text { RIDGE MOISTURE } \\
\text { (RH \%) } \\
(\text { al } 20 \text { minin) }\end{array}$ & 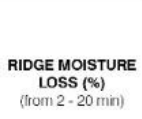 & $\begin{array}{l}\text { MOSS } \\
\text { GROWTH } \\
\text { (weok 12) }\end{array}$ & REMARKS +- \\
\hline 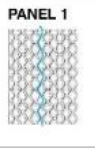 & 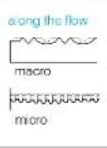 & $\int_{1006}^{1}$ & $\int_{-0.04}^{1} \downarrow$ & 24 & $l_{-4}^{1}$ & $\begin{array}{ll}16 \\
23.1\end{array}$ & $\int_{-4.4}^{1} \downarrow$ & & $\begin{array}{l}\text { - cushion growth with } \\
\text { macro capth } \\
\text { - moderate growth } \\
\text { - low absoiption \& rotention } \\
\text { - low micro dicpth }\end{array}$ \\
\hline PANEL 2 & 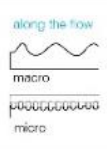 & $\begin{array}{l}1 \\
+0.07\end{array}$ & $\int_{-0.09}^{1}$ & 86 & $\int_{-4.8}^{1} \downarrow$ & $\begin{array}{l}11 \\
19.7\end{array}$ & ${ }_{-7.1}^{1} \downarrow$ & & $\begin{array}{l}\text { - wider \& deeper macro } \\
\text { depth } \\
\text { - lower nidge moisture } \\
\text { - good growh } \\
\text { - low absoiption \& retention } \\
\text { - low micro depth }\end{array}$ \\
\hline 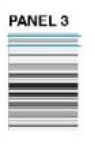 & 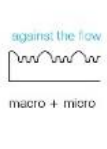 & $\begin{array}{l}46 \\
+0.28\end{array}$ & $\int_{-0.07}^{1} \downarrow$ & 44.6 & $\frac{1}{-3.4}$ & ${ }_{36.1}^{4 \Delta}$ & $\int_{+6.1}^{1} \uparrow$ & 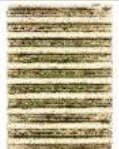 & 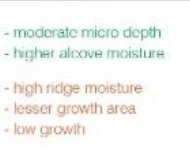 \\
\hline $\begin{array}{r}\text { PANEL 4 } \\
0 \\
4 \\
4\end{array}$ & 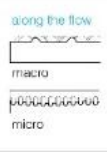 & $\begin{array}{c}1 \\
-0.08\end{array}$ & $\int_{-0.03}^{1} \downarrow$ & 16 & $\int_{-4.4}^{1}$ & 22.6 & $\begin{array}{c}1 \\
-3\end{array}$ & $\frac{204}{8 \%}$ & $\begin{array}{l}\text { - low absorption \& retention } \\
\text { - low macro \& micro depoph } \\
\text { - low and a randorn growth }\end{array}$ \\
\hline PANEL 5 & \begin{tabular}{|l} 
no obstacte \\
mo depth
\end{tabular} & $\begin{array}{l}100 \\
+0.39\end{array}$ & $\int_{-0.03}^{1} \downarrow$ & 25.1 & $c_{-1}^{1}$ & 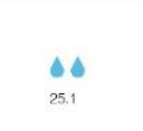 & $c_{-1}^{1}$ & & $\begin{array}{l}\text { - hegh absorpton } \\
\text { - quick drying } \\
\text { - no growh }\end{array}$ \\
\hline$\sqrt{3}$ & 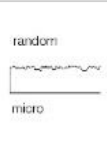 & $\begin{array}{l}\Delta \Delta \Delta \Delta / \\
+0.55\end{array}$ & $\int_{-0.04}^{1} \downarrow$ & $\begin{array}{ll}141 \\
30.2\end{array}$ & -10.1 & $\begin{array}{ll}30.2 \\
301\end{array}$ & $\underset{-16.1}{d}$ & $\frac{16}{2}$ & $\begin{array}{l}\text { - high absorption } \\
\text { - low and randiom growth }\end{array}$ \\
\hline
\end{tabular}

Figure 13. Comparative analysis between water relations at $20 \mathrm{~min}$ after spraying and maximum moss growth results.

According to the analysis of the results, the presence of water was found to be essential for growth, which can be greatly influenced through geometry. The surface roughness or topography was found to be a relevant influencing material characteristic in comparison to its porous quality. This was evident from the high absorption capacity of Panel 5 and Panel 6, with the lowest bio-colonization rate among all of the panels. As it can be seen in Figure 14, in the designed panel, a geometrical combination of macro-depth with deep micro-grooves along a larger surface area can allow better water catchment, while welldefined 'along the flow' macro-geometry can redirect water to growth areas, which can subsequently enhance the bio-receptive quality of the concrete panels.

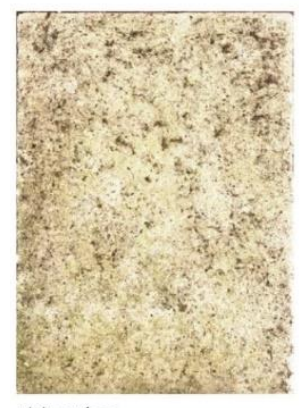

plain surface

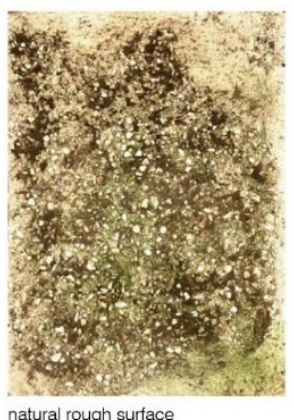

natural rough surface
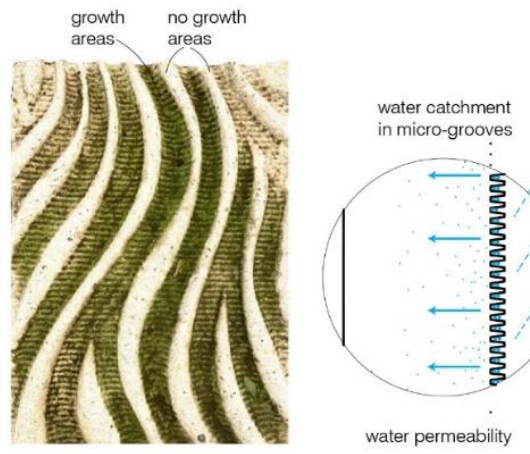

water permeability

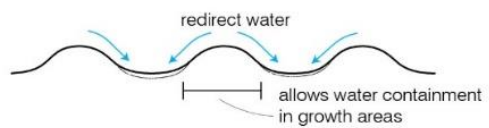

Figure 14. Geometric features to enhance bio-receptive qualities in comparison to natural surfaces. 
Figure 15 provides a feedback loop by highlighting the pros and cons of the geometrical features of the panels that created the maximum positive impact in water absorption/retention on the surface. Features like continuous along-the-flow obstacles in flowing/alternating rhythms helped to direct water to growth areas by prolonging the flow path. Greater macrodepth provided the moist condition to promote cushion growth and deeper micro-grooves helped to increase surface water catchment and gather nutrients. A combination of these positive geometric features arranged in the desired rhythm could create an ordered system that could help enhance the bio-receptive qualities in the vertical position.

\begin{tabular}{|c|c|c|c|c|}
\hline \multicolumn{2}{|c|}{ CHOOSEN PANELS } & $\begin{array}{l}\text { MACRO GEOMETRY/ } \\
\text { OBSTACLE DIRECTION }\end{array}$ & \multirow{2}{*}{$\begin{array}{l}\text { MACRO DEPTH } \\
\mathrm{H}=10-15 \mathrm{~mm} \\
\mathrm{H} M=0.2-0.3 \\
\text { Higher, wider, } \\
\text { smoother ridges }\end{array}$} & \multirow{2}{*}{$\begin{array}{l}\text { MICRO DEPTH } \\
\text { ruvurr } \\
\text { shallow micro-grooves } \\
1-1.5 \mathrm{~mm} \text { depth }\end{array}$} \\
\hline (1) & macro & $\begin{array}{l}\text { Along } \\
\text { the flow } \\
\text { Continuous } \\
\text { obstacles }\end{array}$ & & \\
\hline PANEL 2 & & $\begin{array}{l}\text {-direct water to growth } \\
\text { areas }\end{array}$ & $\begin{array}{l}\text {-quick drying of ridges } \\
\text {-direct growth areas }\end{array}$ & -no water circulation \\
\hline \multirow{2}{*}{ 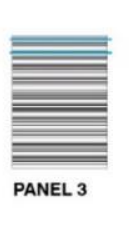 } & \multirow{2}{*}{$\frac{\operatorname{manuns}}{\text { macro + micro }}$} & $\begin{array}{l}\text { Against } \\
\text { the flow } \\
\begin{array}{l}\text { Continuous } \\
\text { obstacles }\end{array}\end{array}$ & $\begin{array}{l}\mathrm{H}=10 \mathrm{~mm} \\
\mathrm{H} / \mathrm{W}-0.5 \\
\text { Higher, wider, } \\
\text { smoother ridges }\end{array}$ & $\begin{array}{l}\text { No/n } \\
\text { deep micro-grooves } \\
3 \mathrm{~mm} \text { depth }\end{array}$ \\
\hline & & $\begin{array}{l}\text {-cannot direct water to } \\
\text { growth areas }\end{array}$ & $\begin{array}{l}\text {-high moisture in ridges } \\
\text {-limited growth area }\end{array}$ & $\begin{array}{l}\text {-water circulation } \\
\text {-vertex created }\end{array}$ \\
\hline \multirow{2}{*}{$\begin{array}{l}382828888 \\
3888888 \\
3888888 \\
3888888 \\
\text { PANEL 1 }\end{array}$} & \multirow{2}{*}{ macro } & $\begin{array}{l}\text { Along } \\
\text { the flow }\end{array}$ & $\begin{array}{l}\mathrm{H}=7 \mathrm{~mm} \\
\mathrm{H} / \mathrm{W}-0.15 \\
\text { low, thin ridges }\end{array}$ & $\begin{array}{l}\text { shurver } \\
\text { shallow micro-grooves } \\
1-1.5 \mathrm{~mm} \text { depth }\end{array}$ \\
\hline & & $\begin{array}{l}\text {-direct water to growth } \\
\text { areas }\end{array}$ & $\begin{array}{l}\text {-shallow ridges } \\
\text {-limit directed growth }\end{array}$ & -no water circulation \\
\hline
\end{tabular}

Figure 15. The pros and cons of the geometry features of the chosen panels.

The problem that was encountered in the moss-growing experiment with the vertical positioning was the fast drying out of the panels due to the absence of the right combination of geometric features, particularly deeper micro-grooves, greater surface areas for growth and along the flow macro-geometries to direct water to growth areas. For the vertical position, what has been learned is that the ability to retain water for a prolonged period, allows the water to slowly seep into the material and create the required micro-climate for the mosses to proliferate.

Therefore, the following design guidelines of the geometric features have been based on the practical results, which can drive the bio-receptive potential of the concrete panels for real-time facade application. Nevertheless, as discussed in the results section, the inoculated panels should be placed in a horizontal position for the initial maturing of the mosses, which can greatly provide a push for better functioning of the geometric features when tested vertically for facade applications.

\subsection{Design Guidelines}

Based on the geometrical analysis so far, a general guideline was provided to create surface geometries that can enhance the bio-receptive character (Figure 16). The type of macro-geometry that is the most suitable is continuous 'along-the-flow' obstacles. These obstacles arranged in a flowing/alternating rhythm can prolong the flow path to varied lengths and promote a continuous trail of growth. From the results of the laboratory 
experiment, a maximum macro-depth of $20 \mathrm{~mm}$ with a $\mathrm{H} / \mathrm{W}$ ratio of $0.2-0.3$ can provide larger defined space for growth and mirror the cushion growth form of mosses in nature. Verified through CFD simulations, a $5 \mathrm{~mm}$ depth of micro-grooves with adjusted $\mathrm{w} / \mathrm{h}$ ratios has been found to create greater water catchment through the increased surface area. In addition to these geometrical features, the absorption capacity of the material is also equally important, which must be adapted according to literature research on bio-receptive material composition. Therefore, these geometric guidelines can be utilized to create a bio-receptive facade, addressing its overall order and balance aesthetic character.

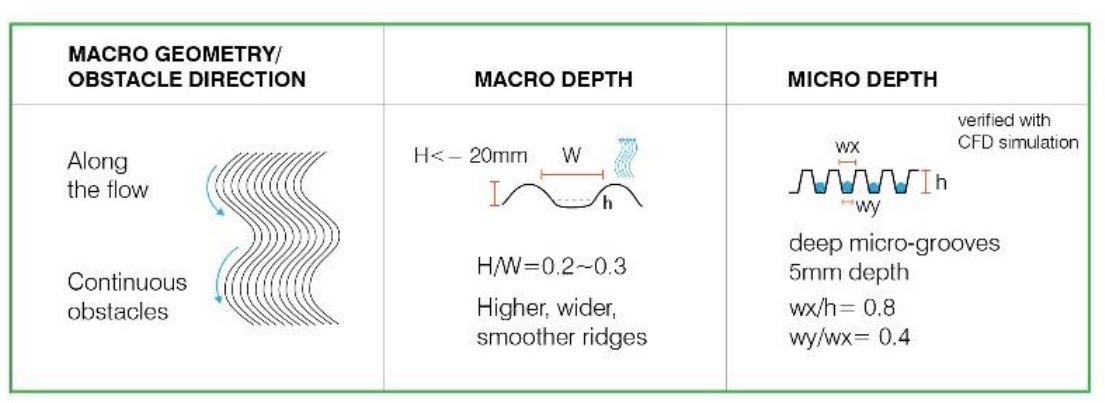

Figure 16. The design guidelines.

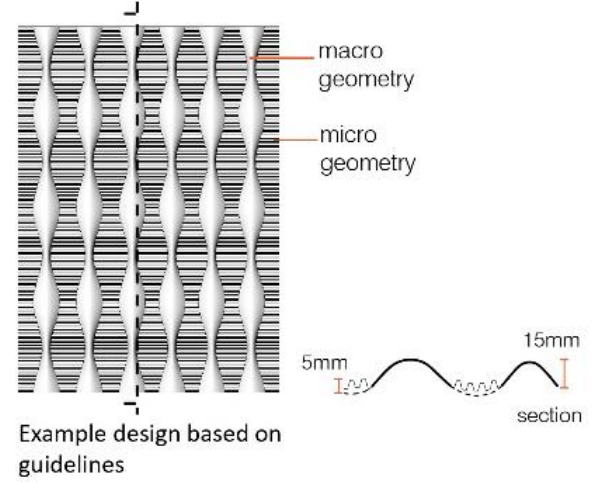

\section{Conclusions}

This research is a testimony that bio-receptive material can be geometrically articulated to engineer a self-sustaining process and manipulate the organic growth of mosses in an ordered system that is not only functionally viable but also aesthetically pleasing, to further change the perception of people towards bio-receptivity. The building material chosen to be investigated was concrete, due to its inherent bio-receptive quality and the capacity to reduce its carbon footprint with a more sustainable and greener version. The research followed a top-down approach where, firstly, designs were developed based on a literature review and field surveys, then the fabricated panels were validated through practical experimentations and finally, a general design guideline was provided.

The presence of water is vital for the growth and development of mosses on stony surfaces. Through the experimentations, the surface roughness or topography was found to be the most crucial feature to create the desired micro-climate for the bio-receptive characteristics of the concrete panels. For vertical application of the panels, the geometric features, like the deep micro-grooves, can create greater water catchment areas on the surface in combination with continuous 'along-the-flow' macro geometries, which can help to direct the flow path, creating a clear distinction between growth and no-growth areas. For the efficient functioning of these geometric features, the initial maturing of the mosses should be allowed in a horizontal position before its vertical application. In support to these geometric features, the material properties of concrete are also equally important as they influence the water absorption capacity of the concrete. The absorption quality of the surface was enhanced by using blast furnace slag cement and a high-water cement ratio of 0.60 in combination with a lack of curing during the hardening process. Using these guidelines, countless options of surface morphology can be used to create a self-sustaining bio-receptive concrete facade panel.

The results of this research work clearly coincide with some of the previous research works where the role of surface roughness or topography in bio-receptivity were established, namely the work of Ottelé et al. and Huang et al. [15]. In the former, the geometry of the top layer of the concrete panel showed an innovative way to foster plant growth on its surface, providing a multifunctional characteristic to a regular construction material. The experiment also provided a clear relationship between the properties of the material and the growth of vegetation on the surface [4]. In the latter, the role of grooves was shown 
to have a significant effect on the concentration of microbial attachment on the substrate, which is a great analogy to the role of micro-grooves in this research [15].

\section{Limitations}

Bio-receptivity is a natural process, and its growth occurs in an unpredictable and spontaneous manner over a prolonged time, typically taking several years. For the time constraint of the research project, an ideal (growth) condition was created in a greenhouse to accelerate and propagate moss growth on the designed concrete panels. The selfsustaining ability of the panels in terms of surface water retention was tested within the controlled setting, which was not necessarily an ideal replica of natural rainfall and moisture conditions. Thus, to control and ensure successful performance of such designed panels in the natural environment, further testing needs to be done in outdoor settings for an extended period, particularly considering their vertical application, before it can be brought into building practice.

Author Contributions: Conceptualization, K.F.M., A.P. and M.O.; methodology, K.F.M.; software, K.F.M.; validation, K.F.M. and A.P.; investigation, K.F.M.; data curation, K.F.M.; writing-original draft preparation, K.F.M.; writing-review and editing, A.P. and M.O.; supervision, A.P. and M.O. All authors have read and agreed to the published version of the manuscript.

Funding: This research received no external funding.

Institutional Review Board Statement: Not applicable.

Informed Consent Statement: Not applicable.

Data Availability Statement: The data presented in this study are contained within the article.

Conflicts of Interest: The authors declare no conflict of interest.

\section{Appendix A}

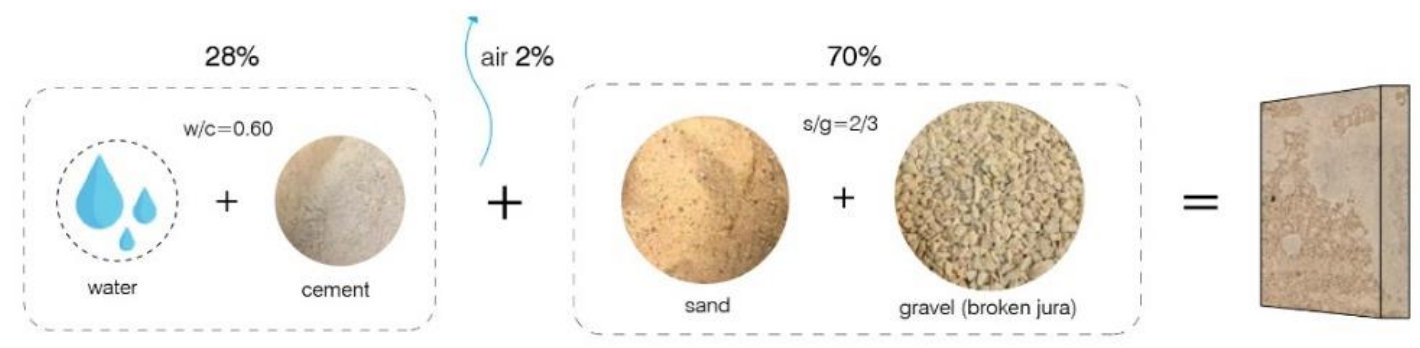

Figure A: Ratio of material used to make concrete blocks

The raw materials:

Density in Tonne Per Cubic Meter $\left(\mathrm{t} / \mathrm{m}^{3)}\right.$

1. Blast furnace cement CBR CEM III/B $32.5 \mathrm{~N}$

with a slag content of $75 \%-\left(2.95 \mathrm{t} / \mathrm{m}^{3}\right)$

2. Concrete sand $0-4 \mathrm{~mm}-\left(2.65 \mathrm{t} / \mathrm{m}^{3}\right)$

3. Broken Jura yellow $5-8 \mathrm{~mm}-\left(2,725 \mathrm{t} / \mathrm{m}^{3}\right)$

4. Water supply - $\left(1.00 \mathrm{t} / \mathrm{m}^{3}\right)$

Figure A1. Cont. 


\section{Calculation:}

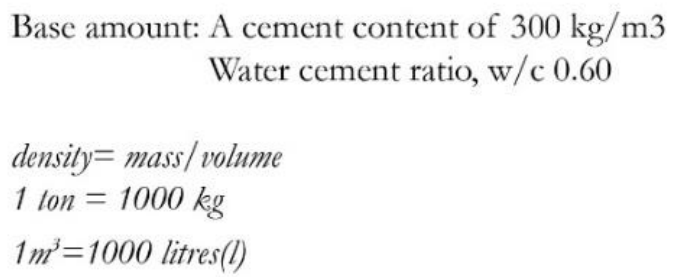

$\left.\begin{array}{l}\text { Concrete } 300 / 2.95=101.7 l \\ \left.\begin{array}{l}\text { Air } 2 \%=20 l \\ \text { Water }=0.60 \times 300=180 l\end{array}\right] 301.7 l\end{array}\right]$

$\begin{aligned} \text { Aggregate materials sand and gravel } & =1000-301.7 \\ & =698.3 \mathrm{l}\end{aligned}$

$40 \%$ sand $0-4 \mathrm{~mm}$

- $>0.40 \times 698.3=279.32 \times 2.65$

$=740 \mathrm{~kg}$ of dry sand

$60 \%$ jurassic yellow $5-8 \mathrm{~mm}$

- $>0.60 \times 698.3=418.98 \times 2,725$

$=1142 \mathrm{~kg}$ dry jurassic yellow
The raw material and the water/cement ratio used are decided according to the literature study to create concrete blocks with lower ph and higher porosity than conventional structural concrete (Figure: A).

\section{$1 \mathrm{~m} 3$ of concrete}

$300 \mathrm{~kg}$ CEM III/B $32.5 \mathrm{~N}$

$740 \mathrm{~kg}$ of dry sand $0-4 \mathrm{~mm}$

$1142 \mathrm{~kg}$ dry jurassic yellow 5-8 mm

180 liters of water

For each tile 3.25 litres are needed and this is mixed in a 10 litres Hobart mixer with a flat mixer.

Material proportion and calculations have been given by Byldis

Figure A1. Material composition for concrete mixture.

\section{References}

1. Lehne, J.; Preston, F. Making Concrete Change. Innovation in Low-Carbon Cement and Concrete; Chatham House, The Royal Institute of International Affairs: Cambridge, UK, 2018.

2. Cruz, M.; Beckett, R. Bioreceptive design: A novel approach to biodigital materiality. Archit. Res. Q. 2016, 20, 51-64. [CrossRef]

3. Manso, S. Bioreceptivity Optimisation Ofconcrete Substratum to Stimulate Biological Colonisation. Ph.D. Thesis, Universitat Politècnica de Catalunya-Departament d'Enginyeria de la Construcció, Barcelona, Spain, 2014.

4. Ottele, M.; Koleva, D.A.; van Breugel, K.; Haas, E.M.; Fraay, A.L.A.; van Bohemen, H.D. Concrete as a multifunctional ecological building material: A new approach to green our environment. In The 19th International Symposium Ecology E Safety; Genov, I., Ed.; Journal of International Scientific Publications Ecology Safety; Info Invest: Burgas, Bulgaria, 2010; Volume 4, pp. $223-234$.

5. Guillitte, O. Bioreceptivity: A new concept for building ecology studies. Sci. Total Environ. 1995, 167, 215-220. [CrossRef]

6. Elbert, W.; Weber, B.; Burrows, S.; Steinkamp, J.; Büdel, B.; Andreae, M.O.; Pöschl, U. Contribution of cryptogamic covers to the global cycles of carbon and nitrogen. Nat. Geosci. 2012, 5, 459-462. [CrossRef]

7. Glime, J.M. Chapter 10: Temperature: Effects. In Bryophyte Ecology Volume 1: Physiological Ecology. 9. 2017. [Ebook sponsored by Michigan Technological University and the International Association of Bryologists]. Available online: http: / / digitalcommons.mtu.edu/bryophyte-ecology / (accessed on 28 November 2019).

8. Haynes, A.; Popek, R.; Boles, M.; Paton-Walsh, C.; Robinson, S.A. Roadside Moss Turfs in South East Australia Capture More Particulate Matter Along an Urban Gradient than a Common Native Tree Species. Atmosphere 2019, 10, 224. [CrossRef]

9. Tomaselli, L.; Lamenti, G.; Bosco, M.; Tiano, P. Biodiversity of photosynthetic micro-organisms dwelling on stone monuments. Int. Biodeterior. Biodegrad. 2000, 46, 251-258. [CrossRef]

10. Miller, A.Z.; Dionísio, A.; Laiz, L.; Macedo, M.F.; Saiz-Jimenez, C. The influence of inherent properties of building limestones on their bioreceptivity to phototrophic microorganisms. Ann. Microbiol. 2009, 59, 705-713. [CrossRef]

11. Tran, T.H.; Hoang, N.D. Estimation of algal colonization growth on mortar surface using a hybrid-ization of machine learning and metaheuristic optimization. Sādhanā 2017, 42, 929-939. [CrossRef]

12. Miller, A.; Sanmartín, P.; Pereira-Pardo, L.; Dionísio, A.; Saiz-Jimenez, C.; Macedo, M.; Prieto, B. Bioreceptivity of building stones: A review. Sci. Total Environ. 2012, 426, 1-12. [CrossRef] [PubMed]

13. D'Orazio, M.; Cursio, G.; Graziani, L.; Aquilanti, L.; Osimani, A.; Clementi, F.; Yéprémian, C.; Lariccia, V.; Amoroso, S. Effects of water absorption and surface roughness on the bioreceptivity of ETICS compared to clay bricks. Build. Environ. 2014, 77, 20-28. [CrossRef]

14. Manso, S.; Calvo-Torras, M.Á.; De Belie, N.; Segura, I.; Aguado, A. Evaluation of natural colonisation of cementitious materials: Effect of bioreceptivity and environmental conditions. Sci. Total Environ. 2015, 512-513, 444-453. [CrossRef] [PubMed] 
15. Huang, Y.; Zheng, Y.; Li, J.; Liao, Q.; Fu, Q.; Xia, A.; Fu, J.; Sun, Y. Enhancing microalgae biofilm formation and growth by fabricating microgrooves onto the substrate surface. Bioresour. Technol. 2018, 261, 36-43. [CrossRef] [PubMed]

16. Dilks, T.J.K.; Proctor, M.C.F. Photosynthesis, respiration and water content in bryophytes. New Phytol. 1979, 82, 97-114. [CrossRef]

17. Bates, J.W. Is 'Life-Form' a Useful Concept in Bryophyte Ecology? Oikos 1998, 82, 223. [CrossRef]

18. Dubosc, A.; Escadeillas, G.; Blanc, P.J. Characterization of biological stains on external concrete walls and influence of concrete as underlying material. Cem. Concr. Res. 2001, 31, 1613-1617. [CrossRef]

19. Soegaard, M. Repetition, Pattern, and Rhythm. Available online: https://www.interaction-design.org/literature/article/ repetition-pattern-and-rhythm (accessed on 21 December 2019).

20. Mutualistic Relationships I Biology for Majors II. Available online: https:/ / courses.lumenlearning.com/wm-biology2/chapter/ mutualistic-relationships / (accessed on 3 March 2020). 